\title{
DATA ANALYSIS AND EVALUATION OF THE ELECTROCHEMICAL PARAMETERS FOR THE ET PROCESS VIA CONVOLUTIVE VOLTAMMETRY AND DIGITAL SIMULATION
}

\author{
I.S. EL-HALLAG I A.M. ASIRI ${ }^{2}$ AND E.H. EL-MOSSALAMY² \\ ${ }^{I}$ Chemistry Department, Faculty of Science, Tanta University, Tanta, Egypt \\ ${ }^{2}$ Chemistry Department, Faculty of Science, King Abdulaziz University, P. O. Box. 80203, Jeddah 21589 Saudi Arabia
}

(Received: December 21, 2012 - Accepted: April 18, 2013)

\begin{abstract}
Data treatment and determination of the standard heterogeneous rate constant of simple ET process (simple electron transfer) \& number of electrons consumed in electrode reaction were carried out via convolution-deconvolution voltammetry and digital simulation methods. The working curves required for determination of the standard heterogeneous rate constant, $k_{\mathrm{s}}$, were constructed and discussed. The number of electrons, $n$, consumed in electrode reaction was calculated via simple method. The electro-reduction of $\mathrm{Pb}^{2+}$ was carried out at hanging mercury drop electrode while the redox behaviour of $\mathrm{Fe}^{3+} / \mathrm{Fe}^{2+}$ couple was performed at glassy carbon electrode to confirm the validity of the reported method in calculation of $k_{\mathrm{s}}$ and $n$ in case of simple ET.
\end{abstract}

Keywords: ET process; convolutive voltammetry; digital simulation; electroactive species; working curves.

\section{INTRODUCTION}

It was established that when the dimensionless parameter $\Psi \geq 7$, the heterogeneous rate constant of electron, $k$, of the electrode reaction is fast, while in case of $\Psi<0.001$ the rate of electron transfer of electrode reaction is slow. In the region of $\Psi$ between 0.001 and 7.0 is that of so-called moderate fast electron transfer. ${ }^{1}$ The correlation between $\Psi$ and $k_{\mathrm{s}}$ is indicated in the following equation: ${ }^{1}$

$$
\Psi=\frac{k_{s}}{(\pi D n F v / R T)^{1 / 2}}
$$

As shown $\Psi$ is a function of heterogeneous rate constant of electron, $k_{\mathrm{s}}$, and scan rate, $v$, i.e. $\Psi$ increase with increasing $k_{\mathrm{s}}$ and decrease with increasing $v$.

The exact peak separation $\left(\Delta E_{\mathrm{p}}\right)$ as a function of $\Psi$ is given in the working curve established by Nicholson. ${ }^{1}$ It was found that when $\Delta E_{\mathrm{p}}>250 \mathrm{mV} / \mathrm{n}$, the calculation of standard heterogeneous rate constant, $k_{\mathrm{s}}$, is inaccurate. This means that the useful range of the working curve for the determination of $k_{\mathrm{s}}$ is $59 \leq \Delta E_{\mathrm{p}} \leq 250 \mathrm{mV} / \mathrm{n}$.

The present work gives an alternative accurate method for data analysis via construction of the working curves for determination of the heterogeneous rate constant $\left(k_{s}\right)$ of the simple electron transfer scheme in the range 10 to $1 \times 10^{-}$ ${ }^{6} \mathrm{~cm} . \mathrm{s}^{-1}$. It was found that, our proposed method minimize the error arising in calculation of the standard heterogeneous rate constant $\left(k_{\mathrm{s}}\right)$ determined from tabulation method especially when $\Delta E>250 \mathrm{mV} / \mathrm{n}$. The electro-reduction of $\mathrm{Pb}^{2+}$ ion in $0.1 \mathrm{M} \mathrm{KNO}_{3}$ at $\mathrm{HMDE}$ and the redox behaviour of $\mathrm{Fe}^{3+} / \mathrm{Fe}^{2+}$ system in $1 \mathrm{M} \mathrm{HCl}$ at glassy carbon electrode (GCE) were taken as an experimental examples of simple ET. The heterogeneous rate constant of these ions was determined via the constructed working curves in the present article. Also, this work provide a simple and accurate method for determination of the number of electrons consumed in electrode reaction.

The convolution transforms $I_{1}$ is defined as following:

$$
I_{1}=\frac{1}{(\pi)^{1 / 2}} \int_{0}^{\mathrm{t}} \quad \begin{aligned}
& i(u) \\
& -(t-u)^{1 / 2}
\end{aligned}
$$

where $i(u)$ is the current at time $u$ and $t$ is the total elapsed time..$^{2-7}$

The electrochemical parameters used for generating the theoretical cyclic voltammograms of the electrochemical reaction

$$
(\mathrm{A}+\mathrm{ne} \leftrightarrow \mathrm{B}) \text { are: }
$$

\footnotetext{
$D_{A}=D_{B} \quad$ (diffusion coefficient of species A and B)

$\mathrm{E}^{0} \quad$ (standard reduction potential)

$\alpha \quad$ (transfer coefficient)

$\mathrm{E}_{\mathrm{s}} \quad$ (switching potential)
}

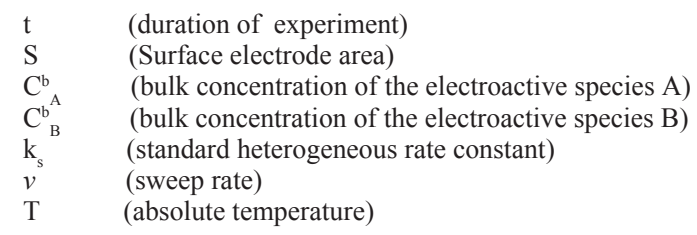

\section{EXPERIMENTAL}

Hydrates salts of the "laboratory grade" $\mathrm{Pb}\left(\mathrm{NO}_{3}\right)_{2}$ was used as solute and a source of $\mathrm{Pb}^{2+}$ ion. Solution of $\mathrm{Pb}^{2+}$ ion $\left(2 \times 10^{-4} \mathrm{M}\right)$ in triple distilled water containing $0.1 \mathrm{M} \mathrm{KNO}_{3}$ solution were investigated. Also hydrates salts of $\mathrm{FeCl}_{3}$ $/ \mathrm{FeCl}_{2}$ was the solute and the source of $\mathrm{Fe}^{3+} / \mathrm{Fe}^{2+}$ pair $\left(5 \times 10^{-4} \mathrm{M}\right)$ in $1 \mathrm{M} \mathrm{HCl}$. A hanging mercury drop electrode (Model 303 A) working electrode (area $=2.61 \times 10^{-2} \mathrm{~cm}^{2}$ ) and GCE (area $=1.2 \times 10^{-2} \mathrm{~cm}^{2}$ ) were used as working electrodes for $\mathrm{Pb}^{2+}$ and $\mathrm{Fe}^{3+} / \mathrm{F}^{2+}$ ions respectively, $\mathrm{Ag} / \mathrm{AgCl}$ reference electrode and $\mathrm{Pt}$ wire as counter electrode were used. . Prior to the electrochemical experiments, solutions were deoxygenated by passage of $\mathrm{N}_{2}$ gas.

A model 264 A Polarographic Analyzer (from EG \& G) was coupled with the cell for $\mathrm{CV}$ experiments. Scan rates used ranged from $0.05-5 \mathrm{Vs}^{-1}$.

The simulation and convolutive voltammetry were performed using finite differences techniques. ${ }^{8,9}$ Algorithms were coded and implemented into condesim software package supplied by EG \& G.

\section{RESULTS AND DISCUSSION}

Fig. 1A shows an example response of the cyclic voltammogram of $\mathrm{Pb}^{2+}$ ion and theoretical cyclic voltammograms of fast and slow ET at sweep rate of $1.0 \mathrm{~V} . \mathrm{s}^{-1}$ and $\mathrm{T}=296 \mathrm{~K}$.

In order to evaluate the heterogeneous rate constant of electron transfer $\left(k_{\mathrm{s}}\right)$, the simulated electrochemical system consists of the reduction of electroactive species proceeds as simple ET was carried out. The arbitrary standard reduction potential $\left(E^{0}\right)$ was $0.5 \mathrm{~V}$ and the diffusion coefficient $(D)$ was equal to $5 \times 10^{-9}$ $\mathrm{m}^{2} \cdot \mathrm{s}^{-1}$. The potential was usually scanned between $0.0 \mathrm{~V}$ (initial value) and -1.0 $\mathrm{V}$ (switching value at fast ET); while for totally irreversible charge transfer, i.e. for $\Psi<1 \times 10^{-3}$, the voltage window of the voltammogram was between 0.0 and $-1.2 \mathrm{~V}$. From the values of peak characteristics of the generated cyclic voltammograms $\left(E_{\mathrm{p}}-E_{\mathrm{p} / 2}, E_{\mathrm{p}}-E^{0}, E_{\mathrm{p} / 2}-E^{0}\right.$ and $\left.\Delta E_{\mathrm{p}}\right)$ as a function of $\Psi$, working curves were constructed with unprecedented treatment of the investigated simple ET scheme. The values of $E_{\mathrm{p}}-E^{0}$ used for preparing the working curves was in the range 28.3 to $629 \mathrm{mV}$, while $\Psi$ values ranging from 572.9 to $4 \times 10^{-6}$ for peak separation, $\Delta E_{\mathrm{p}}, 57.0-1257.0 \mathrm{mV} / \mathrm{n}$ at $\alpha=$ 0. 5. Fig. 2 shows the constructed working curve of the plot $E_{\mathrm{p}}-E^{0}$ vs. $\log$ $\Psi$ scale. On the other hand, when $\alpha=0.3$ the values of $\Psi$ cover the range $0.130-4.04 \times 10^{-5}$ in case of variation $\Delta E_{\mathrm{p}}$ from 217.4 to $1205.0 \mathrm{mV} / \mathrm{n}$. From the measured values of wave characteristics, the corresponding values of $\Psi$ can be calculated, which consider accurate and simple way for determination of the true value of $k_{\mathrm{s}}$. 
Inspection of Table 1 revealed that, there is an agreement between the values of $k_{\mathrm{s}}$ evaluated from working curves established in this work and from tabulation method $^{1}$ when $\Delta E$ in the range $59-250 \mathrm{mV} / \mathrm{n}$. On the other hand, when $\Delta E_{\mathrm{p}}>250 \mathrm{mV} / \mathrm{n}$, there is a disagreement between the values of $k_{\mathrm{s}}$ calculated from tabulation curve and $k_{\mathrm{s}}$ calculated in this article indicate the inaccuracy of the tabulation method established in literature.

(A)

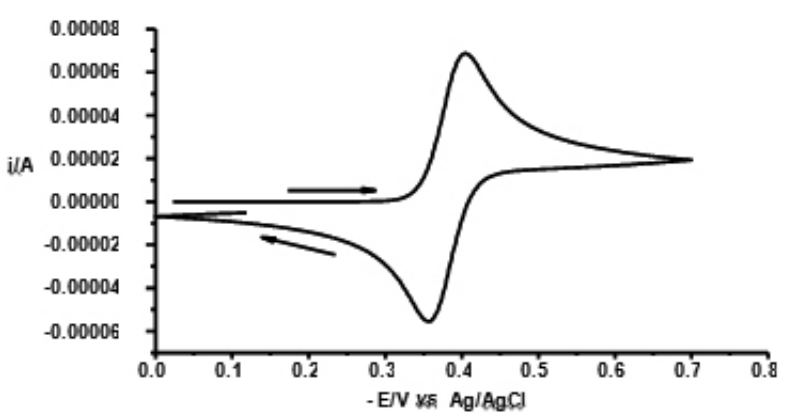

(B)

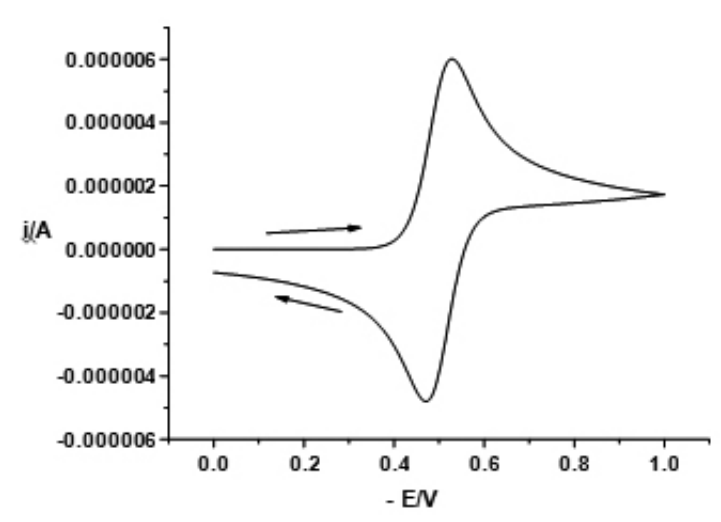

(C)

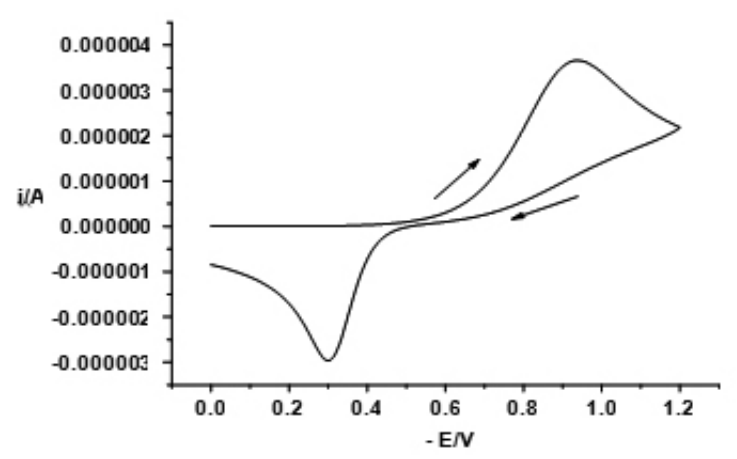

Fig.1. Cyclic voltammograms for $\mathrm{Pb}^{2+}$ ion in $0.1 \mathrm{M} \mathrm{KNO}{ }_{3}(\mathrm{~A})$, theoretical fast ET , $\mathrm{ks}=10 \mathrm{cms}^{-1}(\mathrm{~B})$ and theoretical slow ET, $k_{\mathrm{s}}=10^{-6} \mathrm{cms}^{-1}(\mathrm{C})$ at sweep rate of $1 \mathrm{Vs}^{-1}$.
Table 1: Values of $\Psi$ and $k_{\mathrm{s}}$ determined from this work and from other methods.

\begin{tabular}{|c|c|c|c|c|c|}
\hline \multicolumn{2}{|c|}{$\Psi$} & \multirow[b]{2}{*}{ (A) } & \multicolumn{3}{|c|}{$k_{\mathrm{s}}, \mathrm{cm} \cdot \mathrm{s}^{-1}$} \\
\hline this work & ref.[1] & & this work & ref.[1] & (B) \\
\hline 572.9 & --- & 100.0 & 10.000 & --.- & 10.0 \\
\hline 127.0 & -..-. & 99.00 & 9.990 & -..-. & 10.0 \\
\hline 57.0 & --.- & 99.99 & 0.990 & -.-- & 1.0 \\
\hline 18.1 & 21.30 & 99.96 & 0.990 & 1.170 & 1.0 \\
\hline 5.72 & 6.00 & 100.0 & 1.000 & 1.049 & 1.0 \\
\hline 4.04 & 5.40 & 99.80 & 0.990 & 1.133 & 1.0 \\
\hline 1.28 & 2.00 & 100.0 & 1.000 & 1.111 & 1.0 \\
\hline 0.91 & 1.07 & 100.00 & 1.000 & 0.084 & 1.0 \\
\hline 0.57 & 0.67 & 100.0 & 0.100 & 0.092 & 0.1 \\
\hline 0.404 & 0.53 & 99.7 & 0.090 & 0.093 & 0.1 \\
\hline 0.046 & 0.036 & 99.9 & 0.091 & 0.089 & 0.1 \\
\hline 0.018 & 0.017 & 100.0 & $1.00 \mathrm{E}-3$ & $1.68 \mathrm{E}-3$ & $1 \mathrm{E}-3$ \\
\hline 0.013 & -..- & 99.0 & $0.99 \mathrm{E}-3$ & & $1 \mathrm{E}-3$ \\
\hline $5.70 \mathrm{E}-3$ & -.-- & 100.0 & $1.00 \mathrm{E}-3$ & & $1 \mathrm{E}-3$ \\
\hline $4.04 \mathrm{E}-3$ & & 99.0 & $0.99 \mathrm{E}-3$ & & 1E-3 \\
\hline 4.04E-4 & & 99.9 & $0.99 \mathrm{E}-3$ & & 1E-3 \\
\hline $5.70 \mathrm{E}-5$ & & 100.0 & $1.00 \mathrm{E}-4$ & & $1 \mathrm{E}-4$ \\
\hline $1.20 \mathrm{E}-5$ & & 100.0 & $1.00 \mathrm{E}-4$ & & $1 \mathrm{E}-4$ \\
\hline $9.00 \mathrm{E}-6$ & & 99.9 & $0.994 \mathrm{E}-5$ & & 1E-5 \\
\hline $5.70 \mathrm{E}-6$ & & 99.5 & $0.995 \mathrm{E}-5$ & & 1E-5 \\
\hline $4.00 \mathrm{E}-6$ & & 99.9 & $0.999 \mathrm{E}-5$ & & $1 \mathrm{E}-5$ \\
\hline \multicolumn{6}{|l|}{$\alpha=0.3$} \\
\hline 0.127 & & 99.8 & $9.97 \mathrm{E}-3$ & & $1 \mathrm{E}-2$ \\
\hline 0.090 & & 99.7 & $9.95 \mathrm{E}-3$ & & $1 \mathrm{E}-2$ \\
\hline 0.040 & & 99.5 & $9.95 \mathrm{E}-3$ & & $1 \mathrm{E}-2$ \\
\hline 0.028 & & 99.5 & $9.98 \mathrm{E}-3$ & & $1 \mathrm{E}-2$ \\
\hline 0.018 & & 99.8 & $1.00 \mathrm{E}-3$ & & $1 \mathrm{E}-3$ \\
\hline 0.012 & & 100.0 & $9.98 \mathrm{E}-4$ & & $1 \mathrm{E}-3$ \\
\hline $5.72 \mathrm{E}-3$ & & 99.8 & $9.99 \mathrm{E}-4$ & & $1 \mathrm{E}-3$ \\
\hline $4.04 \mathrm{E}-3$ & & 99.9 & $9.99 \mathrm{E}-4$ & & $1 \mathrm{E}-3$ \\
\hline $1.80 \mathrm{E}-4$ & & 99.9 & $9.99 \mathrm{E}-5$ & & $1 \mathrm{E}-4$ \\
\hline $5.72 \mathrm{E}-5$ & & 99.9 & $9.98 \mathrm{E}-5$ & & $1 \mathrm{E}-4$ \\
\hline 4.04E-5 & & 99.8 & $9.95 \mathrm{E}-6$ & & $1 \mathrm{E}-5$ \\
\hline
\end{tabular}

(A) percentage of accuracy of the $k_{\mathrm{s}}$ value extracted from working curve established in this work to the value of $k_{\mathrm{s}}$ used in simulated CV, (B) Values of $k_{\mathrm{s}}$ used for generating cyclic voltammograms.

It was found that the value of the heterogeneous rate constant $\left(k_{\mathrm{s}}\right)$ of $\mathrm{Pb}^{2+}$ ion in $0.1 \mathrm{M} \mathrm{KNO}_{3}$ calculated from the working curve established in this work equals $\left(2.25 \times 10^{-2} \mathrm{~cm} \cdot \mathrm{s}^{-1}\right)$ which compare well with the value $\left(2.10 \times 10^{-2} \mathrm{~cm} \cdot \mathrm{s}^{-1}\right)$ reported in literature ${ }^{10}$ confirming the accuracy of our method. Also the value of $k$ for the system $\mathrm{Fe}^{3+} / \mathrm{Fe}^{2+}$ calculated in this work $\left(3.41 \times 10^{-4} \mathrm{~cm} . \mathrm{s}^{-1}\right)$ compare well with the value established in literature $\left(3.0 \times 10^{-4} \mathrm{~cm} . \mathrm{s}^{-1}\right){ }^{2}$

It was found that deconvolution voltammetry $y^{7,11-18}$ is a particular efficient tools in qualitative and quantitative electroanalysis. The action of semi differentiation operator ' $e$ ' on a current is to generate a quantity defined by

$$
\mathrm{d} I_{1} / \mathrm{d} t=\mathrm{d}^{1 / 2} i / \mathrm{d} t^{1 / 2}
$$

which is defined as the deconvolution of the current with respect to time. ${ }^{7}$ The ratio of the forward $\left(\mathrm{d} I_{1} / \mathrm{d} t\right)_{\mathrm{f}}$ and backward $\left(\mathrm{d} I_{1} / \mathrm{d} t\right)_{\mathrm{b}}$ peak height of deconvolution voltammetry 19 is taken as a simple and accurate tool for testing and verifying the simple ET of the electrode process similar to the ratio of peak current $\left(i_{\mathrm{ph}} / i_{\mathrm{pf}}\right)$ measured from cyclic voltammogram. It was found that, the ratio $(\mathrm{d} I / \mathrm{d} t)_{\mathrm{f}} /(\mathrm{d} I / \mathrm{d} t)_{\mathrm{b}}$ equals 1.0 and independent on the value of scan rate in the case of rapid and slow charge transfer (Table 2).

The values of the most significant quantities of wave characteristics of cyclic and deconvolution voltammetry at arbitrary values of $\Psi$ and transfer coefficient $(\alpha=0.3 \& 0.5)$ are listed in Table 3 . The plots of $\log \Psi$ versus peak width of the deconvoluted current $\left(W^{\mathrm{p}}\right)$ and the separation between the forward and backward peak potentials of the deconvoluted current $\left(\Delta e_{p}\right)$ of the generating cyclic voltammograms shown in Fig. 3 allow the evaluation of standard heterogeneous rate constant in the range 10 to $1 \times 10^{-6} \mathrm{cms}^{-1}$.

Also, the number of electrons consumed in electrode reaction can be calculated from combination between the limiting convoluted current $\left(I_{\text {lim }}\right)$ and the peak current $(i)$ for fast and slow ET as following: ${ }^{7,17}$ 


$$
\begin{aligned}
& \quad \begin{array}{l}
\left(i_{\mathrm{p}}\right)_{\text {rev }}=\left(2.69 \times 10^{5}\right) n^{3 / 2} S D^{1 / 2} v^{1 / 2} C^{\mathrm{b}} \\
\stackrel{=}{=} 2.788 I_{\text {lim }}(n v)^{1 / 2}
\end{array} \\
& \text { and } \\
& \quad\left(\mathrm{i}_{\mathrm{p}}\right)_{\mathrm{irr}}=2.99 \times 10^{5} n\left(\alpha n_{\mathrm{a}}\right)^{1 / 2} S C^{\mathrm{b}} D^{1 / 2} v^{1 / 2} \\
& \stackrel{=}{=} 3.099 I_{\mathrm{lim}}\left(\alpha n_{\mathrm{a}}\right)^{1 / 2} v^{1 / 2}
\end{aligned}
$$

where $I_{\lim }=n F S C^{b} D^{1 / 2}, \alpha$ is the transfer coefficient, $n_{\mathrm{a}}$ is the number of electrons exchanged in the rate determining step, and the other terms have their usual meanings. Eqs (4) \& (5) can be write in the following forms:

$$
\begin{aligned}
& \quad\left(i_{\mathrm{p}}\right)_{\mathrm{rev}} / I_{\lim }=2.788(n v)^{1 / 2} \\
& \quad(n)^{1 / 2}=\left(i_{\mathrm{p}}\right)_{\mathrm{rev}} / 2.778 I_{\lim }(v)^{1 / 2} \\
& \text { and } \quad \\
& \left(i_{\mathrm{p}}\right)_{\mathrm{irr}} / I_{\lim }=3.099\left(\alpha n_{\mathrm{a}}\right)^{1 / 2} v^{1 / 2} \\
& \left(\alpha n_{\mathrm{a}}\right)^{1 / 2}=\left(i_{\mathrm{p}}\right)_{\mathrm{irr}} / 3.099 I_{\lim }(v)^{1 / 2}
\end{aligned}
$$

Table 2: The dependence of the ratio of the forward peak height to the backward peak height $\left(e_{\mathrm{pt}} / e_{\mathrm{pb}}\right)$ of deconvolution voltammetry on the sweep rate at $k_{\mathrm{s}}=0.1 \mathrm{~cm} \cdot \mathrm{s}^{-1}$ and $k_{\mathrm{s}}=10^{-6} \mathrm{~cm} \cdot \mathrm{s}^{-1}$.

\begin{tabular}{ccc}
$\begin{array}{c}\text { Scan rate } \\
\text { V.s }\end{array}$ & $\begin{array}{l}k_{\mathrm{s}} \\
\mathrm{cm} \cdot \mathrm{s}^{-1}\end{array}$ & $e_{\mathrm{pf}} / e_{\mathrm{pb}}$ \\
\hline & & \\
0.05 & 0.1 & 1.00 \\
0.10 & & 1.00 \\
0.20 & & 1.00 \\
0.50 & & 1.00 \\
1.00 & & 1.00 \\
2.00 & & 1.00 \\
5.00 & & 1.02 \\
& \multirow{2}{*}{$10^{-6}$} & \\
0.05 & & 1.01 \\
0.10 & & 1.02 \\
0.50 & & 1.01 \\
1.00 & & 1.03 \\
2.00 & & 1.04 \\
5.00 & & 1.02 \\
& &
\end{tabular}

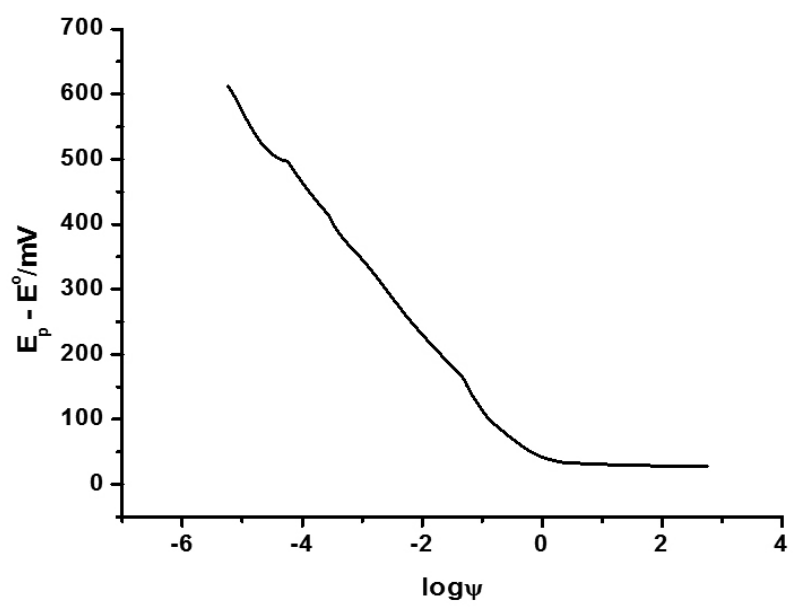

Fig.2. Working curve of $E_{\mathrm{p}}-E^{\circ} v s \log \Psi$ for simple ET, $\alpha=0.5$ and $\mathrm{T}=298 \mathrm{~K}$.

Also, in the same manner, the ratios $\left(\left(\mathrm{d} I_{1} / \mathrm{d} t\right)_{\mathrm{f}} / i_{\mathrm{p}}\right)$ and $\left(\left(\mathrm{d} I_{1} / \mathrm{d} t\right)_{\mathrm{f}} / I_{\text {lim }}\right)$ for reversible and irreversible electrode processes can be written in the following form:

$$
\begin{gathered}
\left(\left(\mathrm{d} I_{1} / \mathrm{d} t\right)_{\mathrm{f}} / I_{\text {lim }}\right)_{\text {rev }}=\frac{n F I_{1 \text { lim }} v}{-4 I_{1 \text { lim }} R T}=9.736 n v \\
\mathrm{n}=\frac{\left(\mathrm{d} I_{1} / \mathrm{d} t\right)_{\mathrm{f}}}{--.736 I_{1 \text { im }} v}
\end{gathered}
$$

$$
\begin{aligned}
& \left(\left(\mathrm{d} I_{\mathrm{l}} / \mathrm{d} t\right)_{\mathrm{f}} / i_{\mathrm{p}}\right)_{\mathrm{rev}}=\frac{n F I_{\text {lim }} v^{1 / 2}}{--n^{1 / 2}} \\
& =3.492 n^{1 / 2} v^{1 / 2} \\
& (n)^{1 / 2}=\frac{\left(\mathrm{d} I_{1} / \mathrm{d} t\right)_{\mathrm{f}}}{3.492\left(i_{\mathrm{p}}\right)_{\text {rev }}(v)^{1 / 2}} \\
& \left(\left(\mathrm{~d} I_{1} / \mathrm{d} t\right)_{\mathrm{f}} / I_{\text {lim }}\right)_{\text {irr }}=\frac{\alpha n F I_{\text {lim }} v}{--3.367 R T I_{\text {lim }}}=11.566 \alpha n v
\end{aligned}
$$

$$
\alpha n=\frac{\left(\mathrm{d} I_{1} / \mathrm{d} t\right)_{\mathrm{f}}}{---.566 I_{1 \text { lim }} v}
$$

$$
\begin{aligned}
\left(\left(\mathrm{d} I_{1} / \mathrm{d} t\right)_{\mathrm{f}} / i_{\mathrm{p}}\right)_{\text {irr }} & =\frac{\alpha n F I_{\text {lim }} v}{10.434\left(\alpha n_{\mathrm{a}}\right)^{1 / 2} I_{1 \text { im }} R T v^{1 / 2}} \\
& =3.73\left(\alpha / n_{\mathrm{a}}\right)^{1 / 2} n v^{1 / 2} \\
\alpha & \left(\left(\mathrm{d} I_{\mathrm{l}} / \mathrm{d} t\right)_{\mathrm{f}}\right)_{\text {irr }} \\
(-----)^{1 / 2}= & 3.73 n i_{\text {pirr }} v^{1 / 2}
\end{aligned}
$$

where $(e)=(\mathrm{d} I / \mathrm{d} t)_{\mathrm{f}}=n^{2} F^{2} S C^{\mathrm{b}} D^{1 / 2} v / 4 R T$ and $\left(e_{\mathrm{pf}}\right)_{\mathrm{irr}}^{\mathrm{pf}}=\left(\mathrm{d} I_{1} / \mathrm{d} t\right)_{\mathrm{f}}=\left(\alpha n^{2} F^{2} S C^{\mathrm{b}} D^{1 / 2} v / 3.367 R T\right)$

(A)

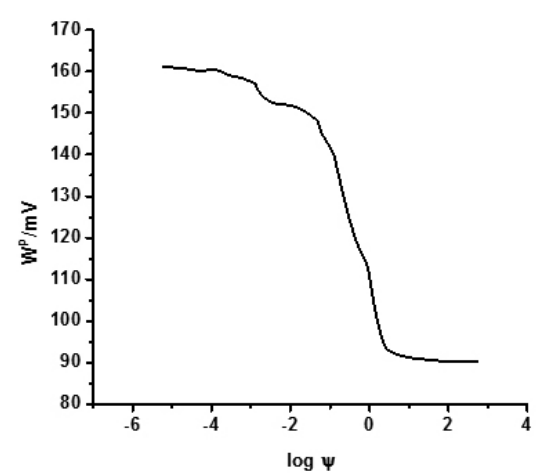

(B)

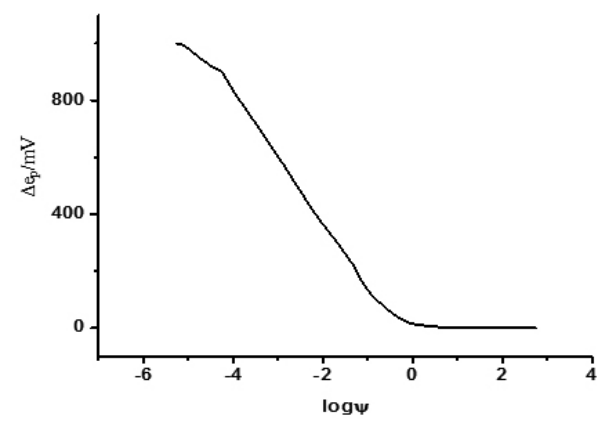

Fig. 3. Working curves for Simple ET: $W^{\mathrm{p}} v s \log \Psi$ (A) and $\Delta \mathrm{e}_{\mathrm{p}} v s \log$ $\Psi(\mathrm{B})$ 
(A)

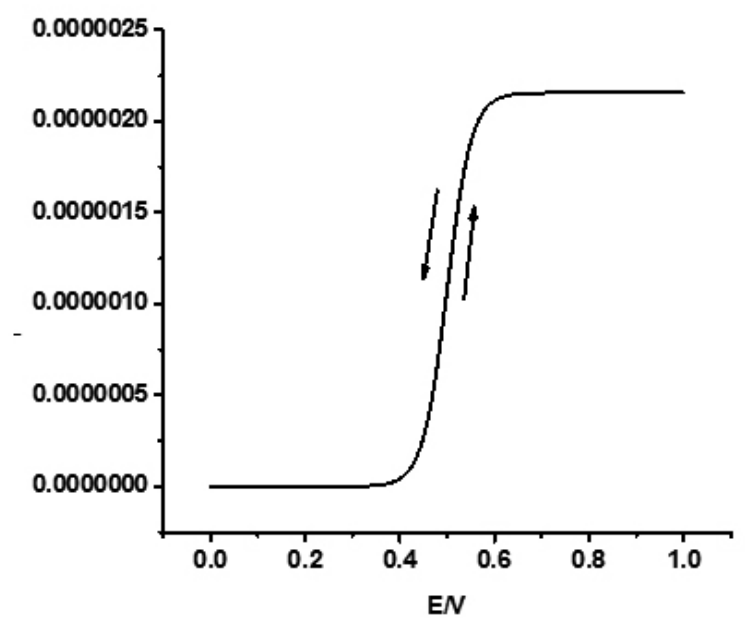

(B)

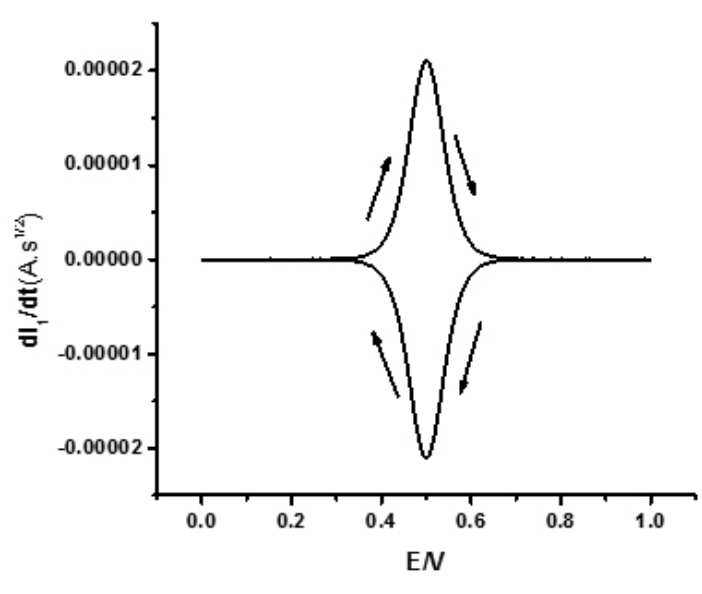

Fig.4. Convolution voltammogram (A) and deconvolution voltammogram (B) of fast ET.

Table 3: The values of peak characteristics and $\Psi$ obtained from theoretical cyclic voltammograms and their deconvolution voltammetry at $\alpha=0.5 \& 0.3$.

\begin{tabular}{|c|c|c|c|c|c|c|c|}
\hline$\Delta E_{\mathrm{p}}$ & $E \mathrm{p}-E_{\mathrm{p} / 2}$ & $E \mathrm{p}-E^{\circ}$ & $E_{\mathrm{p} / 2}-E^{0}$ & $W^{p}$ & $e_{\mathrm{pf} /} / e_{\mathrm{pb}}$ & $\Delta e \mathrm{p}$ & $\Psi$ \\
\hline \multicolumn{8}{|l|}{$\alpha=0.5$} \\
\hline 57.0 & 57.1 & 28.3 & -30.4 & 90.3 & 1.0 & 0.0 & 572.9 \\
\hline 57.0 & 57.1 & 28.3 & -30.4 & 90.3 & 1.0 & 0.0 & 127.9 \\
\hline 58.2 & 57.8 & 29.3 & -30.3 & 90.3 & 1.0 & 0.0 & 57.2 \\
\hline 58.5 & 58.2 & 29.8 & -30.4 & 91.0 & 1.0 & 0.0 & 18.1 \\
\hline 62.0 & 60.1 & 32.6 & -28.3 & 91.3 & 1.0 & 0.0 & 5.7 \\
\hline 65.2 & 60.1 & 32.6 & -23.9 & 92.5 & 1.0 & 4.0 & 4.04 \\
\hline 66.0 & 63.0 & 32.9 & -26.1 & 93.0 & 1.0 & 8.0 & 2.90 \\
\hline 71.8 & 64.0 & 34.8 & -26.1 & 95.7 & 1.0 & 9.0 & 1.81 \\
\hline 78.2 & 65.2 & 39.1 & -26.1 & 104.2 & 1.0 & 13.0 & 1.28 \\
\hline 87.0 & 69.6 & 43.5 & -26.1 & 113.0 & 1.0 & 17.0 & 0.91 \\
\hline 100.0 & 73.9 & 52.2 & -26.1 & 117.4 & 1.01 & 30.4 & 0.57 \\
\hline 117.4 & 78.3 & 60.9 & -17.4 & 117.9 & 1.02 & 39.1 & 0.40 \\
\hline 195.7 & 87.0 & 100.0 & 13.0 & 139.6 & 1.11 & 113.1 & 0.128 \\
\hline 226.1 & 89.2 & 119.6 & 30.4 & 143.4 & 1.06 & 139.1 & 0.090 \\
\hline 275.0 & 90.5 & 142.0 & 46.9 & 144.0 & 1.04 & 182.7 & 0.060 \\
\hline 311.0 & 100.1 & 162.0 & 60.0 & 148.0 & 1.01 & 217.3 & 0.050 \\
\hline 391.0 & 101.0 & 200.0 & 100.0 & 151.0 & 1.05 & 304.3 & 0.020 \\
\hline 424.0 & 101.1 & 217.0 & 119.6 & 152.0 & 1.09 & 339.1 & 0.013 \\
\hline 506.0 & 106.1 & 256.0 & 160.9 & 152.0 & 1.09 & 416.0 & $5.7 \mathrm{E}-3$ \\
\hline 543.0 & 109.0 & 274.0 & 180.4 & 152.0 & 1.06 & 456.0 & $4.04 \mathrm{E}-3$ \\
\hline 628.3 & 115.8 & 317.0 & 219.0 & 152.2 & 1.06 & 539.1 & $1.81 \mathrm{E}-3$ \\
\hline 667.4 & 120.9 & 334.0 & 239.0 & 153.0 & 1.07 & 578.3 & $1.28 \mathrm{E}-3$ \\
\hline 702.1 & 124.3 & 354.0 & 256.0 & 157.0 & 1.19 & 608.7 & $9.04 \mathrm{E}-4$ \\
\hline 785.0 & 130.4 & 378.0 & 299.0 & 158.0 & 1.03 & 699.0 & $4.04 \mathrm{E}-4$ \\
\hline 817.4 & 132.0 & 413.0 & 315.0 & 159.0 & 1.05 & 730.5 & $2.86 \mathrm{E}-4$ \\
\hline 877.4 & 139.1 & 434.0 & 337.0 & 159.0 & 1.01 & 778.3 & $1.81 \mathrm{E}-4$ \\
\hline 902.3 & 141.0 & 451.0 & 357.0 & 160.0 & 1.09 & 807.0 & $1.28 \mathrm{E}-4$ \\
\hline 988.0 & 142.3 & 497.0 & 395.0 & 161.0 & 1.04 & 900.0 & $5.70 \mathrm{E}-5$ \\
\hline 1008.0 & 143.9 & 503.0 & 397.0 & 160.0 & 1.09 & 935.0 & $1.81 \mathrm{E}-5$ \\
\hline 1170.0 & 145.0 & 591.0 & 493.0 & 161.0 & 1.02 & 1000.0 & $9.00 \mathrm{E}-6$ \\
\hline 1223.0 & 148.0 & 612.0 & 514.0 & 161.0 & 1.01 & 1000.0 & $5.70 \mathrm{E}-6$ \\
\hline $\begin{array}{c}1257.0 \\
\alpha=0.3\end{array}$ & 151.1 & 629.0 & 538.0 & 161.0 & 1.09 & 1008.0 & $4.04 \mathrm{E}-6$ \\
\hline 217.0 & 134.8 & 139.1 & 4.0 & 208.7 & 1.09 & 108.7 & 0.130 \\
\hline 256.6 & 147.9 & 169.6 & 21.0 & 239.1 & 1.07 & 147.0 & 0.090 \\
\hline 354.3 & 158.7 & 239.1 & 80.4 & 241.2 & 1.00 & 247.8 & 0.040 \\
\hline 400.0 & 159.6 & 269.6 & 113.0 & 256.6 & 1.03 & 291.4 & 0.028 \\
\hline 416.0 & 159.0 & 285.0 & 175.7 & 164.0 & 1.09 & 346.9 & 0.021 \\
\hline 452.2 & 160.9 & 308.7 & 177.8 & 248.0 & 1.06 & 356.5 & 0.018 \\
\hline 495.6 & 160.8 & 339.1 & 178.3 & 248.0 & 1.07 & 391.3 & 0.013 \\
\hline 632.0 & 161.0 & 434.0 & 278.3 & 256.0 & 1.01 & 530.0 & $4.04 \mathrm{E}-3$ \\
\hline 879.9 & 162.0 & 605.0 & 443.5 & 269.0 & 1.03 & 773.0 & $5.72 \mathrm{E}-4$ \\
\hline 921.9 & 164.0 & 638.0 & 473.9 & 276.0 & 1.07 & 818.0 & $4.04 \mathrm{E}-4$ \\
\hline 1023.0 & 167.0 & 706.0 & 549.0 & 276.0 & 1.05 & 914.7 & $1.80 \mathrm{E}-4$ \\
\hline 1159.0 & 171.0 & 803.0 & 642.0 & 282.0 & 1.01 & 1062.0 & $5.72 \mathrm{E}-5$ \\
\hline 1205.0 & 173.0 & 833.0 & 672.0 & 286.0 & 1.03 & 1095.0 & $4.04 \mathrm{E}-5$ \\
\hline
\end{tabular}


Table 4: The numerical values of the ratios of peak current height of cyclic voltammograms, deconvolution voltammetry, limiting current and the number of electrons calculated via these ratio in case of fast and slow electron transfer for theoretical and experimental work.

\begin{tabular}{|c|c|c|c|c|c|c|c|c|}
\hline $\begin{array}{c}\text { Scan rate } \\
\text { V.s. }\end{array}$ & $\left(i_{\mathrm{p}}\right)_{\mathrm{rev}} / I_{\lim }$ & $(i p)_{\text {irr }} / I_{\lim }$ & $\left(e_{\mathrm{pf}}\right)_{\mathrm{rev}} / I_{\mathrm{lim}}$ & $\left(e_{\mathrm{pf}}\right)_{\mathrm{irr}} / I_{\mathrm{lim}}$ & $\left(e_{\mathrm{pf}}\right)_{\mathrm{rev}} /\left(i_{\mathrm{p}}\right)_{\mathrm{rev}}$ & $\left(e_{\mathrm{pf}}\right)_{\text {irr }} /\left(i_{\mathrm{p}}\right)_{\mathrm{irr}}$ & $n$ & \\
\hline \multicolumn{9}{|c|}{ Theoretical work } \\
\hline 005 & 0,625 & 0,491 & 0488 & 0.292 & 0782 & 0.491 & (a) & (b) \\
\hline 0.10 & 0.885 & 0.695 & 0.973 & 0.582 & 1.107 & 0.695 & 1.007 & 1.0 \\
\hline 0.20 & 1.252 & 0.984 & 1.947 & 1.165 & 1.567 & 0.984 & 1.008 & 1.0 \\
\hline 0.50 & 1.965 & 1.554 & 4.853 & 2.917 & 2.740 & 1.554 & 0.994 & 1.0 \\
\hline 1.0 & 2.781 & 2.199 & 9.683 & 5.820 & 3.877 & 2.199 & 1.008 & 1.0 \\
\hline 2.0 & 2.800 & 2.200 & 19.393 & 11.657 & 4.654 & 2.640 & 0.987 & 1.0 \\
\hline 5.0 & 6.17 & 4.912 & 47.800 & 29.179 & 8.680 & 4.912 & 0.996 & 1.0 \\
\hline 10.0 & 8.729 & 6.950 & 95.359 & 58.211 & 11.060 & 6.950 & 0.985 & 1.0 \\
\hline \multicolumn{9}{|c|}{$\begin{array}{l}\text { Experimental work } \\
\mathrm{Pb}^{2+} \text { ion }\end{array}$} \\
\hline 0.1 & 1.245 & & 1.947 & & 1.564 & & 2.005 & 2.0 \\
\hline 0.2 & 1.764 & & 3.889 & & 2.204 & & 2.001 & 2.0 \\
\hline 0.5 & 2.783 & & 9.712 & & 3.488 & & 2.000 & 2.0 \\
\hline 1.0 & 3.938 & & 19.375 & & 12.633 & & 1.995 & 2.0 \\
\hline \multicolumn{9}{|c|}{$\mathrm{Fe}^{3+} / \mathrm{Fe}^{2+}$ pair } \\
\hline 0.05 & & 0.142 & & 0.0242 & & & 0.9999 & 1.0 \\
\hline 0.10 & & 0.288 & & 0.0971 & & & 0.9995 & 1.0 \\
\hline
\end{tabular}

(a) Average values of $n$ calculated via Eqs. 6 - 11 established in this work.

(b) Values of $n$ used in generating cyclic voltammograms.

Hence, Eqs. (6-11) can be used as a simple route for determination of $n$, $\alpha, n_{\mathrm{a}}$ of the electroactive species without knowing the electrode surface area and without knowing the bulk concentration of the electroactive species. Fig. 4 indicates an example response of convoluted and deconvoluted current of fast ET system.

Table 4 includes the computed values of the ratios and $n$ obtained from Eqs 6- 11. It was found that, the values of $n$ calculated in this article agree well with that used in generating the cyclic voltammograms in case of theoretical work (Table 4). On the other hand, in case of electrode reaction of $\mathrm{Pb}\left(\mathrm{NO}_{3}\right)_{2}$ and $\mathrm{Fe}^{3+} / \mathrm{Fe}^{2+}$ systems in aqueous media, the value of $n$ calculated from Eqs. $6-11$ is equal to $1 \pm 005$ in case of the electrode reaction of $\mathrm{Fe}^{3+} / \mathrm{Fe}^{2+}$ pair and $2 \pm$ 0.005 in case of electro-reduction of $\mathrm{Pb}^{2+}$ ion which agree with the values of $n$ reported in literature..$^{2,10}$

\section{CONCLUSION}

A simple and accurate method for evaluating the heterogeneous rate constant $k_{\mathrm{s}}$, via cyclic voltammetric data and convolution deconvolution procedures for simple ET systems has been developed. From the above discussion it is clear that the most applications of theoretical data established in the present work are the tabulation and plotting of the dimensionless parameters, $\Psi$, vs. $E-E^{0}, W^{p}$ , $\Delta e_{\mathrm{p}}$ for elucidation of the experimental phenomena as well as the estimation of the number of electrons involved in the electrode reaction.

\section{REFERENCES}

1.- RS. Nicholson, Anal. Chem. 37, 1351, (1965).

2.- YI. Moharram, Monat. Fur. Chem. 128, 1208, (1997).

3.- KB. Oldham, J. Electroanal. Chem. 145, 9, (1983).

4.- A. Blagg, SW. Carr, GR. Cooper, ID. Dobson, JB. Gill, DC. Goodall, BL. Shaw, N. Taylor, T. Boddington, J. Chem. Soc. Dalton Trans. 1213, (1985).

5.- DD. Macdonald, Transient Techniques in Electrochemistry. Plenum Press, New York, 1977.

6.- KB. Oldham, J. Spanien, The Fractional Calculus, Academic Press, New York, 1974.

7.- ID. Dobson, N. Taylor, LRH. Tipping, Electrochemistry Sensors and Analysis. Elsevier. Amsterdam, 61, 1986.

8.- SW. Feldberg, Digital simulation in electrochemistry in AB. Bard, Electroanalytical chemistry, Vol. 3. Dekker, New York, 1969.

9.- D. Britz, Digital simulation in electrochemistry, Springer-Verlag, Berlin, 1981.
10.- IS. El-Hallag, B. Electrochem. 14, 44, 1998.

11.- PD. Alford, M. Goto, KB. Oldham, J. Electroanal. Chem. 85, 1, 1977.

12.- IS. El-Hallag, AM. Hassanien, MM. Ghoneim, Monat. Fur. Chem. 126, $1075,1995$.

13.- IS. El-Hallag, Annali di Chimica. 84, 443, 1994.

14.- M. Goto, D. Ishii, J. Electroanal. Chem. 61, 361, 1975.

15.- PD. Alford, M. Goto, KB. Oldham, Anal. Chem. 49, 1390, 1977.

16.- JJ. Toman, SD. Brown, Anal. Chem. 53, 1497, 1981.

17.- RS. Nicholson, I. Shain, Anal. Chem. 36, 706, 1964.

18.- AM. Asiri, SA. Khan, IS. El-Hallag, J. New. Mater. Electrochem. 14, 251, 2011.

19.- HM. Al-Bishri, EH. El-Mossalamy, IS. El-Hallag, S. El-Daly, J. Korean Chem. Soc. 55, 169, 2011. 